\title{
Study of Alterations in Liver Function Tests Following Laparoscopic Surgery
}

\author{
Dr P Rama Rao ${ }^{1}$,Dr Shruti Kongara ${ }^{2}$,Dr Y Snigdha ${ }^{3}$,Dr K.A.S.S.N. Kalyan ${ }^{3}$ \\ ${ }^{1}$ Associate Professor, General Surgery, Dr.Pinnamaneni Siddhartha Institute ofMedical Sciences \&Research \\ Foundation, India. \\ ${ }^{2}$ Junior Resident, General Surgery, Dr.Pinnamaneni Siddhartha Institute ofMedical Sciences \&Research \\ Foundation, India. \\ ${ }^{3}$ Junior Residents, General Surgery, Dr.Pinnamaneni Siddhartha Institute ofMedical Sciences \&Research \\ Foundation, India.
}

\begin{abstract}
Laparoscopic surgery has revolutionized the field of general surgery and has gained worldwide popularity and acceptance. However as it became more prevalent new concerns arose regarding the adverse effects of carbon dioxide pneumoperitoneum and increased intra-abdominal pressure during laparoscopic procedures. This is a prospective study, where blood samples were collected from 60 inpatients, undergoing various laparoscopic procedures, preoperatively once and post operatively on days 1 and 3 . They were tested for liver function by assessing levels of serum bilirubin, serum alanine amino transferase (ALT), serum aspartateaminotransferase (AST) and serum alkaline phosphatase (ALP). The level of serum AST, ALT, bilirubin and alkaline phosphatase increased significantly during the immediate post-operative period. Doubling of pre-op values of AST was seen in $28.3 \%$ and of ALT was seen in $25 \%$. By the $3^{\text {rd }}$ post-operative day, levels of AST, ALT, bilirubin and alkaline phosphatase returned to near pre-operative values. Therefore, transient elevation of hepatic enzymes occurred after all types of laparoscopic procedures. This transient rise showed no apparent clinical implication in most patients. However in those with hepatic insufficiency, care should be taken before deciding to perform laparoscopic surgery.
\end{abstract}

Keywords: Carbon dioxide, Laparoscopy, Laparoscopic surgery,LFTs, Pneumoperitoneum.

\section{Introduction}

Minimally invasive surgery, especially laparoscopic surgery, has changed the face of general surgery. Laparoscopy provides access to the peritoneal cavity for diagnosis and for many surgical interventions that were previously possible only by laparotomy. Its advantages are well recognized and include reduced post-operative pain, shorter length of hospital stay and superior cosmetic results. Some of the diseases, which were not tackled due to fear of damage to surrounding structures during access, are presently being treated easily with laparoscopic surgery. Laparoscopy has had a profound influence on management of patients with impalpable testes, gallbladder disease and Hirschsprung's disease ${ }^{[1]}$.

However the operation time may be prolonged and the pneumoperitoneum produces elevated intraabdominal pressure with continuous compression of intra-abdominal organs, which potentially influences hepatic microcirculatory perfusion ${ }^{[3-5]}$.New concerns arose regarding the effects of pneumoperitoneum on the cardiovascular and respiratory systems ${ }^{[2]}$. Moreover, the observation of hemodynamic and metabolic impairment related to Carbon dioxide $\left(\mathrm{CO}_{2}\right)$ pneumoperitoneum and postoperative mesenteric ischemia reports following laparoscopic procedures have raised concern about the local and systemic effects of increased intraabdominal pressure during laparoscopic procedures.

Many studies have disclosed 'unexplained' changes in postoperative liver function tests (LFTs) in patients undergoing laparoscopic procedures ${ }^{[6,7]}$ It has been noticed that, following laparoscopic surgery, level of certain serum liver enzymes rose markedly in most patients who had shown normal preoperative LFTs. This observation raised several questions - Are these changes of any clinical significance? What is the mechanism responsible? These changes might be attributed to hepatocellular dysfunction secondary to one or combination of $\mathrm{CO}_{2}$ pneumoperitoneum, diathermy extruding liver, branch of hepatic artery injured and general anaesthesia ${ }^{[6]}$. The transient elevation of hepatic enzymes showed no apparent clinical implication in most patients who received laparoscopic surgery according to follow-up observations and feedback from these patients.

However, any increase in liver enzymes is a matter of concern to the clinician and warrants further investigation to determine the underlying pathology. Laparoscopy is gaining wide popularity among surgeons in India. There have been no studies in our setting to evaluate the potential deleterious effects of laparoscopic surgery on hepatic function. This study aims to investigate the alterations in the serum levels of liver enzymes following laparoscopic surgeries performed under constant intraperitoneal pressure $(14 \mathrm{~mm} \mathrm{Hg})$ at Tertiary care teaching hospital. 


\section{Aims And Objectives}

- To evaluate effects of laparoscopic surgery on liver enzymes Aspartate-aminotransferase (AST), Alanineaminotransferase (ALT), alkaline phosphatase (ALP) and serum bilirubin.

- To establish the cause, possible mechanisms and clinical significance of disturbances in liver enzymes following laparoscopy

\section{Materials And Methods}

This prospective controlled study was conducted to evaluate the effectof laparoscopic procedures on liver function. The study population constituted 60 consenting inpatients, selected by purposive sampling from those who underwent various laparoscopic surgeries in a Tertiary care teaching hospital. Prior to selection, they underwent routine history taking, physical examination and investigations to exclude pre-existing liver diseases or generalized debility. Those selected had normal values of serum liver enzymes prior to surgery. The study was conducted over a 2-year period from November 2014 to October 2016. Ethics committee approval was taken.

Data collected included

- Name, age, sex, in patient no.

- Diagnosis, Name of procedure

- Duration of pneumoperitoneum

- Anaesthesia involved

- Levels of :

- AST/SGPT (normal range < 35 U litre-1)

- ALT or SGOT (normal range < 40 U litre-1)

- Serum Bilirubin (normal range $<1 \mathrm{mg} / \mathrm{dL}$ )

- Serum Alkaline Phosphatase (range 60-170 U litre-1)

All measured pre-operatively (pre-op) once and then post-operatively (post-op) on Day 1, Day 3.

During the surgery, the intraabdominal pressure (IAP) was maintained at around $14 \mathrm{mmHg}$. The CO2insufflation time was recorded in each procedure.All patients had a urinary catheter introduced before the surgery. Perioperativeantibiotics were administered in all patients.

The following patients were excluded from the study:

- Patients with coexisting liver disease / preoperative deranged LFTs.

- Patients that developed complications such as bile duct injury, obstruction, infection, leakage and high grade fever during surgery and in the post-operative period.

- Patients who had undergone endoscopic retrograde cholangio pancreaticography(ERCP) and endoscopic sphincterotomy within one week before surgery.

The data was analysed for finding the significance of the effect of laparoscopy on hepatic function by using the students paired $t$ test. All data were expressed as the mean \pm standard deviation. P value less than 0.005 was considered to be statistically significant.

\section{Results}

Out of the 60 patients, who constituted the study population, 38 were females and 22 were male patients. The mean age of the study population was 38.66yrs. Range being from 11 to 69 yrs with majority below 50 years.

Of the 60 patients constituting the study population, 26 patients i.e. $43.3 \%$ underwent cholecystectomy and 18 i.e. $30 \%$ underwent appendectomy. 8 patients had undergone laparoscopic hernia repair for ventral hernias and 2 had undergone transabdominal pre peritoneal repair (TAPP) for inguinal hernia. 


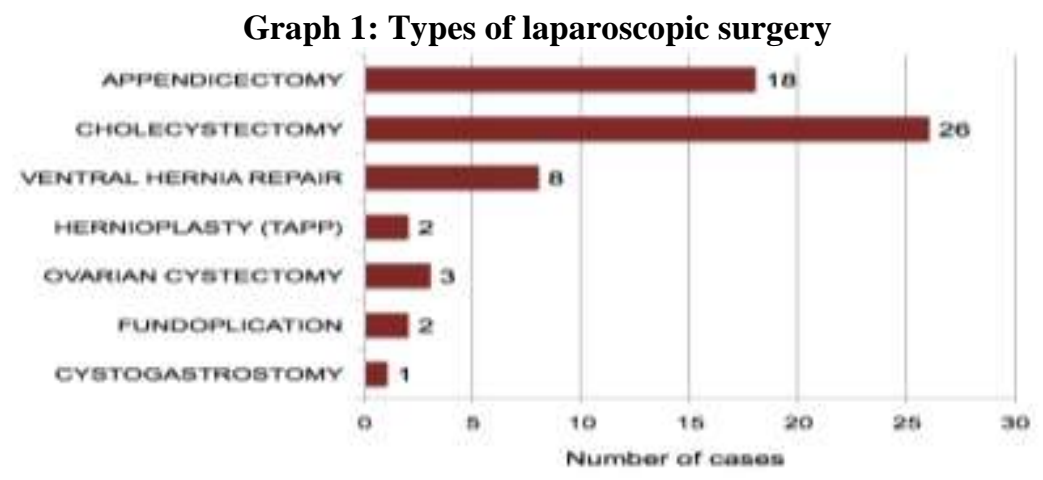

Table 1:Changes in LFTs. Mean distribution of parameters.

\begin{tabular}{|c|c|c|c|}
\hline Parameter & $\begin{array}{c}\text { Pre-op } \\
\text { Mean value }\end{array}$ & $\begin{array}{c}\text { Post-op day 1 } \\
\text { Mean value }\end{array}$ & $\begin{array}{c}\text { Post-op day 3 } \\
\text { Mean value }\end{array}$ \\
\hline Serum bilirubin (mg/dL) & $0.72 \pm 0.156$ & $1.14 \pm 0.321$ & $0.79 \pm 0.155$ \\
\hline AST (IU/L) & $19.23 \pm 6.758$ & $33.00 \pm 12.506$ & $22.40 \pm 7.159$ \\
\hline ALT (IU/L) & $23.10 \pm 6.125$ & $39.37 \pm 12.524$ & $26.82 \pm 7.205$ \\
\hline ALP (IU/L) & $101.03 \pm 21.279$ & $135.517 \pm 31.472$ & $107.583 \pm 22.865$ \\
\hline
\end{tabular}

Graph 2: Comparison of mean Serum Bilirubin value at different time intervals

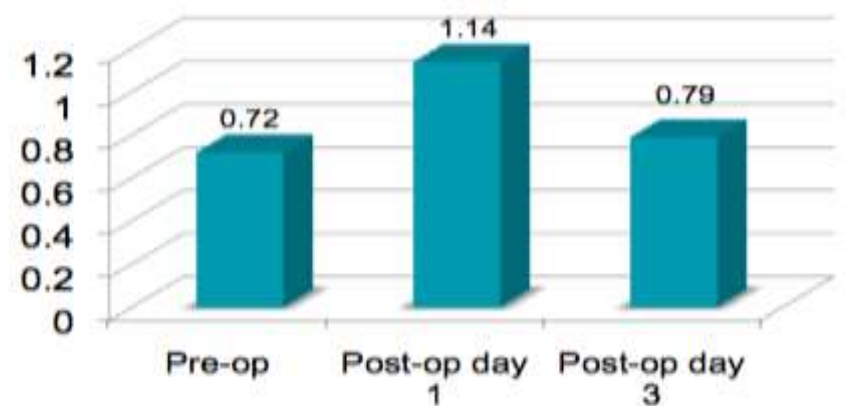

Graph 3: Changes in LFTs after laparoscopic surgery

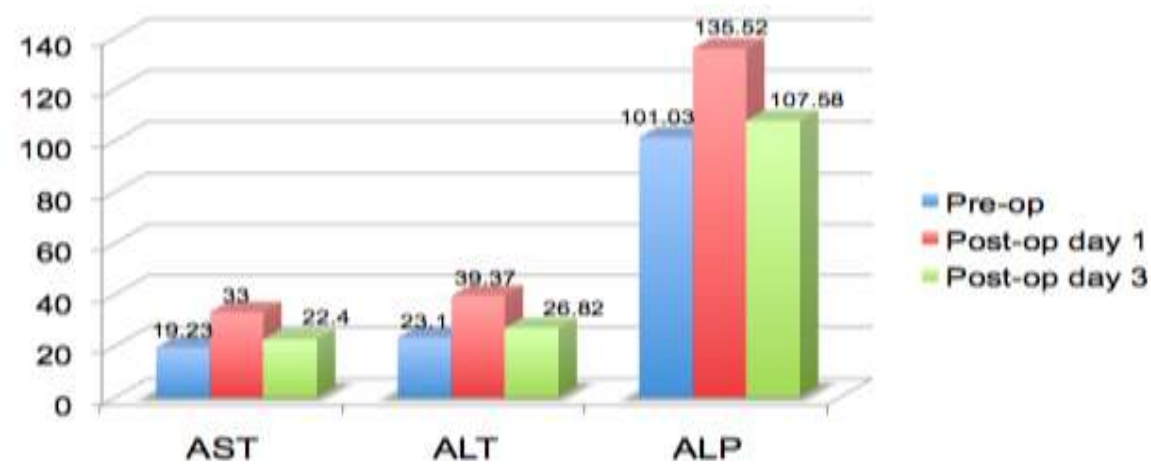

When compared to the pre-operative values, mean values of serum bilirubin, AST, ALT and ALP increased significantly $(\mathrm{p}<0.001)$ by post-operative day 1 and they came down to near pre-op values by post-op day 3 . 


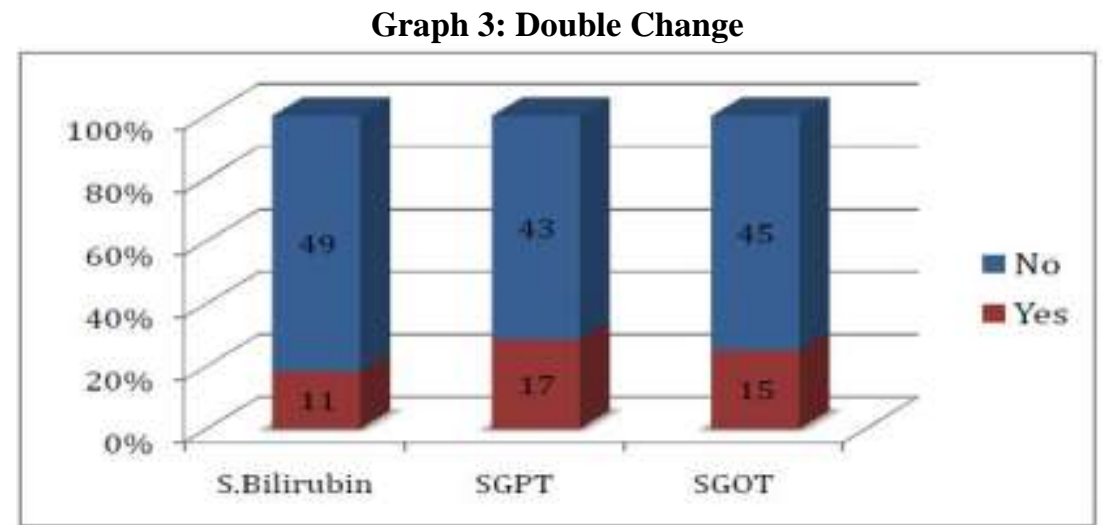

On postoperative day 1 , almost double the preoperative values were found in $18.3 \%$ of patients in the case of serum bilirubin. $28.3 \%$ and $25 \%$ of patients had double their preoperative values on postoperative day 1 , when it came to SGPT and SGOT respectively.

\section{Discussion}

Laparoscopic surgery has become the established method of treatment for many surgical conditions. The progress in laparoscopic procedures has largely been due to the technological advances in endoscopic optics, video cameras and endoscopic instrumentation. Smaller incisions, reduced postoperative pain, shorter hospital stay, early ambulation and return to work are some of the advantages that increased the popularity of laparoscopic procedures ${ }^{[8]}$. Although laparoscopy offered many advantages over laparotomy, new concerns arose regarding the effects of pneumoperitoneum on the cardiovascular and respiratory system. Many studies in the past decade, have disclosed unexplained changes in post-operative liver function in patients undergoing laparoscopic procedures. CO2 pneumoperitoneum might be one of the main reasons for this change in serum liver enzymes, as this is the main difference between laparoscopic and open surgeries.

There have been no studies in our setting, to evaluate the potential deleterious effects of laparoscopic surgery on hepatic function. This study is therefore intended to assess the clinical significance of unexplained disturbances in liver enzymes following laparoscopic surgeries. The post-operative increase seen in the levels of serum bilirubin and liver enzymes was transient and occurred irrespective of the type of laparoscopic surgery they underwent. The values returned to near pre-operative levels within 3 days of surgery. None of the patients presented with post-operative clinical hepatic dysfunction in the follow up period. It was noticed that the postoperative day 1 levels doubled the pre-operative values in $18.3 \%$ of patients in case of serum Bilirubin, $28.3 \%$ of patients had doubling of serum AST levels and $25 \%$ had doubling of serum ALT levels.

Studies have shown changes in serum liver enzymes following laparoscopic surgery, rather than open surgery. The first factor to be considered here is carbon dioxide pneumoperitoneum. All the patients in our study were subjected to carbon dioxide pneumoperitoneum and they showed changes in post-operative serum liver enzymes level. This is consistent with the results of other similar studies. The intra-abdominal pressure of $12-$ $15 \mathrm{mmHg}$ used in our study was higher than the normal portal venous pressure of $7-10 \mathrm{mmHg}$. This might cause a reduction in portal blood flow and lead to alterations in liver function. During laparoscopic surgery, there is an elevation and depression of intra-abdominal pressure (IAP) in a short time, this sudden alteration of IAP could cause undulation of portal blood flow. This undulation in blood flow and re-irrigation of organs may give rise to ischemia and re-irrigation damage of tissues and organs, especially the Kupffer and endothelial cells of hepatic sinusoids ${ }^{9}$. This can cause free radical generation ${ }^{[10]}$. The role of reperfusion related mechanisms after laparoscopy and the production of free radicals are however smaller than the role of total surgical injury during open surgery.

A frequently cited study ${ }^{[1]}$ assessed the splanchnic circulatory changes during high-pressure carbon dioxide pneumoperitoneum. An increase of $5 \mathrm{~mm}$ from 10 to $15 \mathrm{~mm} \mathrm{Hg}$ of the IAP resulted in a blood flow decrease by $39 \%$ to liver and by $60 \%$ to peritoneum, by $40-54 \%$ to stomach, by $32 \%$ to jejunum and by $44 \%$ to colon. Meanwhile it was also found that, splanchnic blood flow decreased along with increase in operative time, despite a constant IAP. The increased IAP also triggers Neurohumoral responses of the vasopressin renin- 
angiotensin-aldosterone system. Vasopressin and norepinephrine play a significant role in causing damage to the hepatic function.

The local effect of prolonged use of diathermy to the liver surface in laparoscopic cholecystectomy and the spread of heat to liver parenchyma may be another possibility ${ }^{[6]}$. This hypothesis is supported by some studies ${ }^{[12-17]}$. However, it remains to be explained why there is hepatic enzyme elevation in laparoscopic surgeries where the focus is far away from the liver. The squeeze pressure effect on the liver may be another possible mechanism for alterations of serum liver enzymes after laparoscopic cholecystectomy ${ }^{[6]}$. The traction of the gall bladder may free the liver enzymes into the blood stream. But it is not significant as similar changes are seen in other laparoscopic surgeries like appendectomy and hernia repairs, where the liver was not handled at all.The rise in mean value of Bilirubin in our study was similar to the studies of Tauro $\mathrm{LF}^{[7]}$ and Praveen Khandelwal $^{[21]}$. Marakis et $a l^{[24]}$ found that the rise in serum bilirubin in LC group was $48.4 \%$, the preoperative mean value was $0.64 \pm 0.24 \mathrm{mg} / \mathrm{dL}$ which showed significant rise to $0.95 \pm 0.58 \mathrm{mg} / \mathrm{dL} 24$ hours after surgery. In the study by Rikki Singal et al ${ }^{[18]}$,the preoperative mean value was $0.53 \pm 0.1 \mathrm{mg} / \mathrm{dL}$, which also showed significant, rise to $1.93 \pm 0.7 \mathrm{mg} / \mathrm{dL}$ after 24 hours of surgery. In our study the pre-operative mean was $0.72 \pm$ $0.16 \mathrm{mg} / \mathrm{dL}$, which increased to $1.14 \pm 0.32 \mathrm{mg} / \mathrm{dL}$ postoperatively. In all the studies, a significant increase in the level of serum bilirubin was seen postoperatively when compared to pre-operative levels. In our study as well as other studies it was seen that this change was transient and that the level of serum bilirubin returned to near pre-operative values by $3^{\text {rd }}$ postoperative day.

Table 2 :Comparison of changes in mean values of AST and ALT afterlaparoscopic surgery in various studies

\begin{tabular}{|l|l|l|l|}
\hline \multicolumn{4}{|l|}{ Mean values of postoperative liver enzyme changes after laparoscopic surgery in various studies } \\
\hline First author (reference) & Enzymes & $\begin{array}{l}\text { Preoperative mean } \\
\text { value (U/l) }\end{array}$ & $\begin{array}{l}\text { Postoperative mean } \\
\text { value (U/l) }\end{array}$ \\
\hline Guven et al. 2007 & AST & $22.76 \pm 6.44$ & $61.72 \pm 28.13$ \\
\hline & ALT & $21.55 \pm 8.92$ & $60.30 \pm 32.17$ \\
\hline Tauro L F et al. 2008 & AST & $19.52 \pm 15.99$ & $30.13 \pm 9.80$ \\
\hline & ALT & $22.57 \pm 5.10$ & $38.63 \pm 12.17$ \\
\hline Khalaf R. Al-Luwaizi 2013 & AST & $11.21 \pm 2.60$ & $32.32 \pm 8.38$ \\
\hline & ALT & $11.48 \pm 2.15$ & $32.37 \pm 8.4$ \\
\hline Rikki Singal et al. 2015 & AST & $27.00 \pm 8.1$ & $72.90 \pm 13.1$ \\
\hline & ALT & $26.0 \pm 8.9$ & $72.4 \pm 12.9$ \\
\hline Our study & AST & $19.23 \pm 6.76$ & $33.00 \pm 12.51$ \\
\hline & ALT & $23.10 \pm 6.12$ & $39.37 \pm 12.52$ \\
\hline
\end{tabular}

The rise in mean values of enzymes in our study was similar to that of other studies as shown in the table above. In the study by Khalaf R. Al-Luwaizi ${ }^{[19]}$, mean pre-operative value of AST in patients undergoing laparoscopic cholecystectomy was found to be $11.21 \pm 2.6$ and postoperatively the mean value rose to $32.32 \pm$ 8.38. In the study by Guven et al ${ }^{[23]}$ the preoperative AST value was $22.76 \pm 6.44$ which increased to $61.72 \pm$ 28.13. In our study the mean value of AST preoperatively and postoperatively was 19.23 and 33 respectively. The results in our study are in agreement with those of other studies, all of which show a significant rise in the values of serum liver enzymes 24 hours postoperatively when compared to preoperative values. It was seen that these changes are transient and that the liver enzyme levels fell within 72 hours postoperatively.

The results in our study are consistent with that of other studies, all of which show a significant rise in postoperative levels of serum liver enzymes AST and ALT as depicted in the table above. These occurred in patients whose preoperative values of liver enzymes were normal. In our study the mean value of ALT preoperatively and postoperatively was 23.1 and 39.37 respectively. In the study by Marakis et al [24]. Preoperative mean value of ALT was 31.88 and postoperatively it increased to 61.62.

These changes did not occur in patients undergoing open surgeries, as compared by Guven et al ${ }^{[23]}$, AlLuwaizi KR et al ${ }^{[19]}$ and Singal $\mathrm{R}$ et al ${ }^{[18]}$, where patients were divided into two groups, one group underwent laparoscopic cholecystectomy and the other open cholecystectomy. There were no significant changes in the levels of serum liver enzymes of patients undergoing open surgery.

Studies by Marakis et al, Guven et al and Singal R et al showed no significant change in the levels of serum alkaline phosphatase postoperatively. This is different from the observations of our study, where the 
mean preoperative value of ALP was 101.03 and on postoperative day 1 it was 135.52 . Our result was similar to that of Tauro LF et al and Khandelwal P et al, where there was a significant rise in the level of serum alkaline phosphatase postoperatively compared to the preoperative value. These changes were transient and they returned to near normal values within a few days postoperatively. However if the serum alkaline phosphatase levels rise above the normal range and if those changes are persistent, further investigation is warranted since persistent elevation of this parameter may be suggestive of a breach in the integrity of biliary tree.

From this study we have observed that the disturbances in liver function tests are not related to the age or sex in relation to laparoscopy. Carbon dioxide pneumoperitoneum, which is the only variable not present in patients undergoing open surgeries, might be one of the major causative factors. An intra-abdominal pressure of 12-14 $\mathrm{mmHg}$ is higher than normal portal blood pressure of 7-10 $\mathrm{mmHg}$, and is therefore capable of reducing portal blood flow and of causing alteration of the hepatic function.

Thus, we conclude that if the patient's pre-operative liver function was very poor, laparoscopic surgery might not be the optimal choice. Alternatives like gasless laparoscopy may help avoid hepatic dysfunction. This could be tried as an alternative to routine laparoscopic surgery using carbon dioxide pneumoperitoneum in patients with poor liver function.

Further work can be carried out in this field by taking a larger sample size, and by taking into consideration the duration of surgery to see if a longer carbon dioxide insufflation time leads to a greater change in postoperative liver enzymes. Also postoperative changes in the levels of liver function tests at different intraabdominal pressures can be compared to see whether low pressure laparoscopic surgery would cause less alterations. This would be beneficial as low pressure laparoscopic surgery or shorter duration of surgery could be adapted in patients with pre-existing liver dysfunction.

\section{Conclusion}

All types of laparoscopic procedures can cause transient elevation of liver enzymes for which Carbon dioxide pneumoperitoneum remains the major causative factor. No apparent clinical implications were seen in patients undergoing laparoscopic surgery having these transient changes. However, they may still cause worry to the surgeon regarding the integrity of biliary tree. If the pre-operative liver function was very poor, laparoscopic surgery might not be the optimal choice for treating certain abdominal diseases and low-pressure pneumoperitoneum or gasless laparoscopy by abdominal wall lifting could be a reasonable alternative.

\section{References}

[1]. Kiely JM, Brannigan AE, Foley E, Cheema S, O'Brien W, Delaney PV. Day case laparoscopic cholecystectomy is feasible. Med Sci. 2001; 170(2):98-99.

[2]. Odeberg-Wernerman S. Laparoscopic surgery - effects on circulatory and respiratory physiology: an overview. Eur J Surg Suppl 2000; 585:4-11.

[3]. Hasukić S. Postoperative changes in liver function tests: randomized comparison of low- and high-pressure laparoscopic cholecystectomy. Surg Endosc 2005 Nov; 19(11):1451-55.

[4]. Schmandra TC, Kim ZG, Gutt CN. Effect of insufflation gas and intraabdominal pressure on portal venous flow during pneumoperitoneum. Surg Endosc 2001; 15: 405-8.

[5]. Saber AA, Laraja RD, Nalbandian HI et al. Changes in liver function tests after laparoscopic cholecystectomy: not so rare, not always ominous. Am Surg 2000; 66:699-702.

[6]. Tan M, Xu FF, Peng JS, Li DM, Chen LH, Lv BJ. et. al. "Changes in the level of serum liver enzymes after laparoscopic surgery." World J Gastroenterol 2003; 9:364.

[7]. Tauro LF, Sheetal CM, Aithala PSM, Shetty SR, D’Souza CS, Rao BSS, Shenoy DH, RaoK. "Evaluation of effects of laparoscopic surgery on hepatic function.” Journal of Clinical Diagnosis and Research 2008; 2 (6): 1155 - 62.

[8]. Sood J, Kumra VP. Anaesthesia for laparoscopic surgery. Indian J Surg 2003; 65: 232-240

[9]. Volz J, Koster S, Spacek Z, Paweletz N. Characteristic alterations of the peritoneum after carbon dioxide pneumoperitoneum. Surg Endosc 1999; 13: 611-614

[10]. Sare M, Yilmaz I, Hamamci D, Birincioglu M, Ozmen M, Yesilada O: The effect of carbon dioxide pneumoperitoneum on free radicals. Surg Endosc 2000; 14:649-652

[11]. Schilling MK, Redaelli C, Krahenbuhl L, Signer C, and Buchler MW: Splanchnic microcirculatory changes during COlaparoscopy. J Am Coll Surg 1997; 184:378- 382

[12]. Tulikangas PK, Smith T, Falcone T, Boparai N, Walters MD. Gross and histologic characteristics of laparoscopic injuries with four different energy sources. Ferti Steril 2001; 75: 806-810

[13]. Capelluto E, Champault G. Variations in intraperitoneal temperature during laparoscopic cholecystectomy. Ann Chir 2000; 125: 259-262

[14]. Barrat C, Capelluto E, Champault G. Intraperitoneal thermal variations during laparoscopic surgery. Surg Endosc 1999; 13: 136138

[15]. Shamiyeh A, Schrenk P, Tulipan L, Vattay P, Bogner S, Wayand W. A new bipolar feedback-controlled sealing system for closure of the cystic duct and artery. Surg Endosc 2002; 16: 812-813 
[16]. Yang W, Benjamin IS, Sherwood R, Alexander B. Correlation of endothelium-dependent and -independent vasodilatation with liver function tests during prolonged perfusion of the rat liver. J Pharmacol Toxicol Methods 1998; 40: 227-234

[17]. Berger M, Junemann K, Schramm H. Danger of monopolar current in laparoscopic gallbladder surgery. Zentralbl Chir 2001; 126: $591-595$

[18]. Singal R, Singal R P, Sandhu K, Singh B, Bhatia G, Khatri A et al. Evaluation and comparison of postoperative levels of serum bilirubin, serum transaminases and alkaline phosphatase in laparoscopic cholecystectomy versus open cholecystectomy. J Gastrointest Oncol 2015; 6(5): 479-486

[19]. Al-Luwaizi KR, Hamad SO. Changes of liver enzymes and serum bilirubin after laparoscopic cholecystectomy. Ann Coll Med Mosul 2013; 39 (2): $113-117$

[20]. Hagras MMAE. Alterations in liver function tests following laparoscopic cholecystectomy. Pak J Surg 2013; 29(4): 245-247

[21]. Khandelwal P, Pradeep YM, Kinhal VA, Ramesh K. Effect of carbon dioxide pneumoperitoneum on liver function in laparoscopic cholecystectomy at Vims, Bellary. International Journal of Scientific Research 2014; 3(9): 377-379

[22]. El-Leathy MM, Abo El-Enin MA, Abd El Aziz IM. Subclinical hepatic dysfunction after laparoscopic surgery in paediatrics. Annals of Paediatric Surgery 2009; 5 (2): 137-140

[23]. Guven HE, Oral S. Liver enzyme alterations after laparoscopic cholecystectomy. J Gastrointestin Liver Dis. 2007; 16 (4): $391-394$

[24]. Marakis G, Pavlidis T, Ballas K, et al. Alterations in Liver Function Tests Following Laparoscopic Cholecystectomy. The Internet J Surg 2006; 8: 245-247

[25]. Sakorafas G, Anagnostopoulos G, Stafyla V, et al. Elevation of serum liver enzymes after laparoscopic cholecystectomy. N Z Med J 2005; 118: U1317

[26]. Giraudo G, Brachet Contul R, Caccetta M, Morino M. Gasless laparoscopy could avoid alterations in hepatic function. Surg Endosc $2001 ; 15: 741-746$ 